\title{
"GOOD TO GREAT" IN PUBLIC RESEARCH UNIVERSITIES
}

\author{
Harvey S. Perlman \\ Chancellor, University of Nebraska-Lincoln \\ and \\ Harvey and Susan Perlman Alumni Professor of Law
}

In April of 2001 I participated in what was, for me, a most unexpected and unnerving event - my installation as Chancellor of the University of NebraskaLincoln. Eighteen years as a law professor and 15 years as dean of a law school hardly prepared me to lead an institution for which graduate education, federally funded research, and technology transfer were the drivers of institutional reputation and success. In search for direction in how to manage an institution as complex and reportedly unmanageable as a research university, I stumbled upon Joe Collins' book "Good to Great." If religious persons return to the Bible when their faith is challenged, then this book has become the bible of my administrative team. The book is a study of why some companies remained good while others became great. Because it is the study of management of private sector companies, one must regard it as a metaphor rather than a set of instructions, but for good or ill we have tried to follow its teachings. The precipitous decline in state revenues and resulting budget cuts during the 20012004 period that would ultimately deprive us of $12 \frac{1}{2} \%$ of our state budget gave us an early opportunity to test its principles.

A brief comment about the University of Nebraska-Lincoln (UNL). It is both the comprehensive research and land-grant institution for the State of Nebraska. It is a member of the Association of American Universities, and the flagship campus of the University of Nebraska system. While it has an illustrious history, in recent years it has consistently underperformed relative to the quality of its faculty. The barriers to innovation and collaboration seemed high and there was too often a fear or resentment toward the celebration of excellence and achievement. Institutional ambitions were modest and such markers as federal competitive grants reflected that modesty. These were not my conclusions; they were the conclusions of a task force consisting of faculty, administrators, and community members who issued a report in $2000{ }^{2}$ Notwithstanding these critiques, we were, in fact, a "good" institution.

In a nutshell, Collins' research identifies three central themes for moving institutions from good to great: The first is getting the right people on the bus,

\footnotetext{
${ }^{1} \mathrm{Jim}$ Collins, Good To Great: Why Some Companies Make the Leap . . . and Others Don't (Harper Business, 2001).

22020 Vision: The Future of Research and Graduate Education at UNL (2000).
} 
then figure out where to drive it. ${ }^{3}$ The second is developing what Collins calls a "hedgehog concept" - that is, establish your priorities at the intersection of three universes: the things that you can be the best in the world at, the things that you are deeply passionate about, and the things that drive your economic engine. The third is to be disciplined in confronting the brutal facts of your situation and in sticking with your priorities. My remarks describe how we have tried to follow this advice in moving our university forward.

\section{Getting the Right People on the Bus}

I had an early opportunity to recast the campus administration. When I took office, I faced three vice-chancellor vacancies and 5 vacant deanships. Either through good fortune or hard work, we were able to attract very talented people, who have worked well as a team. In the recruitment process we followed Collins' advice. We did not measure candidates against our own vision of the future (given my background I hardly had a formulated vision for a research university), but rather listened carefully to the vision that our candidates brought to the table. We have also been less than patient with long-time administrators who had no vision other than retention of the status quo.

Of course, it is far easier to change the composition of an administration than it is to change the composition of a faculty. We had, in my judgment, a remarkably good faculty, but the culture in many departments held down their ambitions and their achievements. As Collins confirms, changing the culture of an institution cannot be dictated from above. Cultural change at the local level occurs from within - a theme that I will revisit - either by the introduction of new blood or by one unit witnessing success in other units.

Shortly before I became Chancellor, the University received an unexpected and largely unrestricted bequest of $\$ 128$ million dollars. My predecessor allocated a significant part of that endowment as matching funds to encourage other donors to fund professorships and chairs. Wisely, he required that the recipient of such chairs could only be faculty recruited from other universities. We now have approximately 24 such endowed professorships which have allowed us to recruit some very gifted senior faculty from other universities. In almost every instance, they have not only brought their prestige to our University, but have also directly upgraded the ambition and the culture of their home departments.

Simultaneously, Prem Paul, as our new Vice Chancellor for Research, was able to stimulate a few selected faculty members toward more collaborative and more ambitious grant requests and had early successes with three, multimillion dollar proposals for federal centers of excellence. Thus, we were fortunate to have provided examples of success, either by hiring successful

\footnotetext{
${ }^{3}$ Collins, at 41 et. seq.
} 
senior faculty, or demonstrating what resident faculty were capable of accomplishing. Moreover, we have now established a tradition of celebrating these achievements with major news conferences and public receptions for faculty who have significant success.

It is more difficult to change personnel within a public university than the private sector so we decided some effort had to be directed toward improving the engagement of our existing faculty and staff. Again, we borrowed from the private sector. The Gallup organization has its headquarters in Nebraska and its long-time Chairman, the late Don Clifton, was a former UNL faculty member. The University had previously partnered with Gallup on a number of academic initiatives and we again sought their help. In addition to the well-known Gallup poll, the company's core business includes consulting with business management on a wide variety of management issues. Clifton is known as the parent of positive psychology, a theory that suggests that, in working with people, one should focus on maximizing their strengths rather than attempting to address their weaknesses.

After considerable empirical research, the Gallup organization has devised a climate survey called the Q12 which consists of 12 questions, the only 12 questions that were shown empirically to have a direct correlation to worker productivity and morale. More significantly, Gallup has developed a process for an organization to undertake to improve its Q12 scores, a process premised on the idea that work climate is created within work groups and that only work groups - here read academic departments - can change the organization-wide working environment.

We have just completed the conduct of the survey for the second time. The introduction of the Q12 to a university setting generated a predictable response. While staff members seemed to respond positively to the survey, faculty began arguing with the structure and nature of the questions and the reliability of the data. (It was fascinating for me to see our faculty attack a survey instrument that had been empirically tested in over 10,000 replications and argue instead for survey questions they had quickly scribbled on napkins.) Nonetheless we have had response rates close to $80 \%$. For me, the survey was not as important as the subsequent process, designed to force departments to meet and develop "impact plans" to improve the engagement of their members. The Q12 survey questions seemed to be intuitively logical and indeed addressed many of the concerns I had received, over time, from the faculty.

For example, the first three questions ask whether as an employee I know what is expected of me at work, whether I have the materials and equipment necessary to do my work right, and whether I have the opportunity to do what I do best every day. With increasing expectations on faculty in multi-mission institutions, one senses faculty frustration with these growing demands as well as the traditional untenured faculty member's complaint about not knowing what 
they need to do to get tenure. These questions address these concerns directly and are the most susceptible, in my opinion, to responsive measures.

The next three questions ask whether I have received recognition or praise for doing good work in the last seven days, whether someone at work cares about me as a person, and whether there is someone at work who encourages my development. Here again, these echo the complaints I frequently hear about the need for faculty mentoring and administrative support. And notwithstanding the academic traditions of independence and selfsufficiency, I believe faculty appreciate and deserve recognition for their successes.

The next four questions relate to whether a faculty member feels a sense of belonging to the department or the institution: my opinions seem to count; the mission of the institution makes me feel my job is important; my associates do quality work; and I have a best friend at work. We have had a lot of highly creative caustic remarks about the "best friend" question, but Gallup tells us the question relates to whether there is someone the person can trust in the workplace. Apparently the question generates considerable resistance in private sector companies as well. As individualistic and self-reliant as faculty purport to be, most of them want to be engaged with their department and institution, although few will readily admit it. And it seems intuitively correct - as well as being empirically verified - that their level of engagement affects their performance. On the whole high achieving faculty tend to be good campus citizens.

The last two questions ask whether someone at work has talked to me about my progress and whether I have had opportunities within the last year to learn and grow. These again reflect concerns I hear about the quality of annual evaluations and the challenge of finding ways to utilize the evolving talents and interests of faculty over the course of their careers.

Whether or not any of this is empirically sound, I can tell you that the overall Q12 scores of individual departments bear a remarkable correlation to my intuitive impressions about the quality of those departments and their willingness and ability to achieve excellence. It is an open question whether I can encourage some of the low scoring departments to actually engage the process of trying to improve their scores, since in departments where faculty are not engaged with each other, these conversations are hard to begin. But the survey results have provoked some very good conversations and actions among some departments and we intend to continue the administration of the survey. We hope to do some activities at the campus and dean level to provide by way of example some efforts to address the survey results. 
Collins describes "hedgehogs" as "dowdy creatures that know 'one big thing' and stick to it." " Trying to develop a "hedgehog concept" for the University presented the most difficult translation from private sector to a public university. The concept requires that you develop priorities that can satisfy three separate criteria: a program at which you can be the best in the world, a program about which you are passionate, and a program that responds to the single greatest impact on your economic success. A private sector company can shed any activity that fails to meet these requirements and can focus on the "one big thing." A public university does not fully control its mission. Private sector companies are measured on the basis of one factor: profit. Public universities are measured on multiple, conflicting, and often contentious factors.

At the University of Nebraska-Lincoln (UNL), I continue to believe the single most important factor driving our economic engine is public support. Notwithstanding the decline in tax support, the people of Nebraska continue to provide approximately one-third of our budget, and those dollars are currently essential to our survival. Thus any hedgehog priority must be such as to merit public support. The narrower and more focused we become, the more narrow our public support. Similarly, while we can think about "one big thing," the very nature of a university is dependent on multiple disciplines, some inevitably stronger or weaker than the others. We could not, for example, decide to do only physics or only English, even though if we focused our resources on either, we would be well on our way of being "best". And, we could not declare our hedgehog to be research alone, since most of the public continues to believe we are a teaching institution, as indeed we are. Moreover, UNL is the state landgrant university with both an obligation and an expectation for outreach and engagement.

The other hedgehog characteristics are also difficult to apply to a research university at the institutional level. The passion of our faculty for any program has a direct correlation to how directly involved they are in the program. And being the "best in the world" requires one to define the "world." For the institution at large we chose to define it as a set of aspirational and yet realistic comparative institutions. ${ }^{5}$

Thus for the institution, our hedgehog concept has become a combination of undergraduate education and research which coincidentally responds to the State's two primary needs: keeping young people in Nebraska and broadening the state's economy. We believe we have a fair shot at being great at

\footnotetext{
${ }^{4}$ Collins, at 119 .

${ }^{5} 2020$ Vision Report, supra, at 53, Exhibit 2.
} 
undergraduate education, and certainly we have areas in research where we might claim to be the best or awfully close. We have also set in motion a prioritization process that will allow each department or cluster of faculty to define their own "hedgehog" - a more fruitful level for a true focus to occur. As a land-grant institution, we have, of course, not ignored our outreach efforts, but we believe that outreach is an extension of teaching and research, not a separate unrelated mission.

In tying undergraduate education and research together, we have acknowledged the historical tension between commitments to teaching and to research. I know it is customary to say there is no conflict between teaching and research and, in theory that is true. On the ground it's quite another matter. I am convinced that a public university must emphasize both, not only to preserve its public support, but also to retain the loyalty and engagement of those faculty whose primary contributions will be on the teaching side of the institution. At least for me, one of the real challenges of managing a research institution is to assure that the voice of teaching is heard over the roar that can be created by highly visible technical innovations and multimillion dollar grant awards. A similar challenge is to find ways to celebrate the research accomplishments of those in the arts and humanities, whose major grants seldom rise above the low six figures. But all of these challenges relate to achieving our "hedgehog" concept.

\section{Discipline in the Face of Brutal Facts}

The most difficult challenge that universities like ours currently face is the effort to remain disciplined and consistent with regard to priorities, and to think in the long-term. Presidents and Chancellors tend to come and go in relatively short order and, as they do, ideas about priorities and hedgehogs tend to change. The result, of course, is few ideas are fully achieved unless one can embed them so deeply into the culture of the institution that no transitory leader would dare depart from them. That would be some trick in a university setting. But we consciously think about ways to do so.

In the relative short-term, our sense of priorities was tested, when, like most public institutions, we faced significant budget reductions during the last two years. Priorities are a lot easier to follow when budgets are increasing. However, we were able during the last two years not only to stick to our priorities but to advance them.

When the prospect of budget cuts became a reality, we decided, after much debate and consideration, that we would respond with vertical reductions, designed to protect our ability to make continuing investments in our priorities. For two rounds we were able to reduce administrative functions, consolidate some outreach efforts, and eliminate some functions that did not involve faculty. However, by the third round, we found it necessary to eliminate three peripheral 
academic programs resulting in the termination of 23 tenured faculty. While all but one of these faculty members were either offered tenured positions by other departments or took early retirement, the outrage by some of the unaffected faculty was intense.

The decision to breach tenure was a very difficult decision and was the product of intense discussion among my senior staff and vice-chancellors. I personally had nothing to lose since my only future ambition is to return to the law school and continue teaching. But others in my administration have much of their careers ahead of them and, being a part of the administration that terminated tenured faculty, seemed unlikely to be career enhancing. In returning to Collins book for reinforcement, we discovered this quote:

Everyone would like to be the best, but most organizations lack the discipline to figure out with egoless clarity what they can be the best at and the will to do whatever it takes to turn that potential into reality. ${ }^{6}$

I am pleased, and a bit surprised, to report that as the smoke has cleared, a vast majority of faculty appear to have supported our decisions. In fact, this decision turned out to be much less contentious around the state than our recent firing of a football coach.

During this same period the Board of Regents set aside approximately $\$ 5$ million dollars of continuing funds to be invested in priority programs. The Board stuck to its decision even though the university was cutting budgets elsewhere. We had earlier engaged a process that asked Deans to surface their own priorities and we now invited each of these programs to submit proposals for these funds. Each proposal required a request for funds, a description of how they would be used, a description of how the proposers would reallocate resources within their own departments to accomplish the priority (after all, if it's a priority when you are asking for new funds, it should be a priority in spending existing resources), the outcome to be expected, and the metrics for measuring success. We currently have 20 priority programs that have received this funding as well as private funding allocated for this purpose. These are local hedgehogs at the departmental or multi-departmental level - the most appropriate place for hedgehogs to inhabit in a university. And we are beginning to see evidence that these programs are elevating their achievements and their aspirations.

\section{Conclusion}

Certainly, UNL as a public research university faces all of the challenges and issues of other research institutions. We are concerned about the reduction in state funding. We are concerned with the international situation that is

\footnotetext{
${ }^{6}$ Collins, at 128
} 
restraining university research and student recruitment. We are working hard to have the research infrastructure keep up with our research success. We are struggling to figure out how to manage technology transfer in a realistic way. But most importantly we are trying to embed into the culture of our university a focused, rigorous, uncompromising commitment to excellence.

And even through one of the most difficult financial periods in the University's, history we have seen competitive grants increase dramatically, we are enrolling an increasing percentage of the "best and the brightest" of graduating Nebraska high school students, we are increasing our non-resident and minority students, and we are recruiting faculty from prestigious universities to join our efforts. We have many more things that need to be accomplished in order for us to claim that we are "great". But, I think, we no longer doubt that we will get there. 